\title{
Prevalence of ESBL in Isolates of Klebsiella pneumoniae and E. coli in Suspected Cases of Neonatal Septicemia in Tertiary Care Hospital in North Maharashtra, India
}

\author{
Wadile Rahul Gopichand*
}

ACPM Medical College, Dhule, India

*Corresponding author

\section{Keywords}

ESBL, Escherichia coli, Klebsiella pneumoniae,

Neonatal septicemia, Blood culture

Article Info

Accepted: 07 April 2019 Available Online: 10 May 2019

\section{A B S T R A C T}

Neonatal sepsis is a significant cause of morbidity and mortality in newborns and is responsible for $30-50 \%$ of total neonatal deaths. Multidrug resistant Gram negative bacilli belonging to the family Enterobcteriaceae have been increasingly responsible for infections among the neonates admitted to the NICU in many countries including India. The study was conducted to know prevalence of ESBL production in Klebsiella pneumoniae and Escherichia coli in NICU so that we can help clinicians to avoid injudicious use of antibiotics. The present study was carried out from July 2017 to December 2018 in Microbiology Department of the rural medical college in North Maharashtra. A total of 200 samples of blood cultures from neonates admitted in the NICU were processed for the study. $2 \mathrm{ml}$ blood from the neonates was collected under aseptic precautions and the samples were inoculated on blood culture bottle containing Brain Heart Infusion (BHI) broth. Gram negative isolates recovered from septicemic cases were further tested for presence of ESBL and resistance pattern. Blood culture is positive in 134 (67\%) among 200 suspected cases of neonatal septicemia. Gram negative isolates are seen in $94(70.15 \%)$ cases whereas Gram positive isolates are seen in $35(26.11 \%)$ cases. The common organism isolated are Klebsiella pneumoniae 53 (39.55\%) followed by Escherichia coli 27 (20.15\%) and Staphylococcus aureus 25 (18.66\%) (Table 1). The ESBL production is more seen in Klebsiella 29 / 53 (54071\%) and Escherichia coli 12/27 (44.44\%). Multidrug resistance is seen in most of the ESBL producing strains which was higher than that seen in no ESBL producing strains. Bacteriological profile of neonatal septicemia varies in different regions of the country like India. Empirical therapy in NICU should be regularly monitored according to the prevalence of ESBL producing organisms in tertiary care centers.

\section{Introduction}

Neonatal sepsis is a significant cause of morbidity and mortality in newborns and is responsible for $30-50 \%$ of total neonatal deaths (Tripathi et al., 2010). The antibiotic susceptibility of microorganisms also changes with time, with the emergence of multidrug resistant organisms (Ballot D et al., 2012). Multidrug resistant Gram negative bacilli 
belonging to the family Enterobcteriaceae have been increasingly responsible for infections among the neonates admitted to the NICU in many countries including India. Klebsiella pneumoniae and Escherichia coli constitutes majority of these pathogens (Jain A et al., 2003). With the emergence of ESBL producing Klebsiella pneumoniae and Escherichia coli as the predominant pathogen, the third generation cephalosporins which have been used extensively as a life saving first line antibiotic among septicemic neonates are rendered useless (Lebessi et al., 2002). Extentended spectrum B lactamases (ESBLs) are plasmid mediated, TEM and SHV derived enzymes, first isolated in Western Europe in mid 1980's, most commonly in Klebsiella spp, followed by E.coli (Chaudhary U et al., 2004).

The study was conducted to know prevalence of ESBL production in Klebsiella pneumoniae and Escherichia coli in NICU so that we can help clinicians to avoid injudicious use of antibiotics and giving susceptible antimicrobials to prevent therapeutic failure in neonates having infection with ESBL positive Klebsiella pneumoniae and Escherichia coli.

\section{Materials and Methods}

The present study was carried out from July 2017 to December 2018 in Microbiology Department of the rural medical college in North Maharashtra. A total of 200 samples of blood cultures from neonates admitted in the NICU were processed for the study.

\section{Definitions}

Early onset neonatal septicemia (EONS) which is defined as infection occurring in either the first $48-72 \mathrm{hrs}$ of life or the first week of life. Late onset sepsis (LONS) is defined as sepsis occurring after $72 \mathrm{hrs}$ or upto 28 weeks of life.
$2 \mathrm{ml}$ blood from the neonates was collected by venepuncture under aseptic precautions and the samples were inoculated on blood culture bottle containing Brain Heart Infusion (BHI) broth (Himedia, Mumbai). The bottles were incubated aerobically at $37^{\circ} \mathrm{C}$ for 7 days. The samples were subcultured on blood agar and MacConkey's agar.

The isolates were identified by colony characteristics, Gram staining, motility and standard biochemical tests. Antibiotic sensitivity test was performed by Kirby Bauer disc diffusion method as per Clinical Laboratory and Standard Institute (CLSI) (Wayne P. A., 2010) using Muller Hinton agar plates (MHA) and commercially procured antibiotic discs (Himedia, Mumbai).

\section{Screening and confirmation of ESBLs}

Screening for ESBL was done according to the CLSI guidelines. All Klebsiella pneumoniae and Escherichia coli isolates were screened for ESBL production by Kirby Bauer disc diffusion method. The isolates showing inhibition zone size of $\leq 22 \mathrm{~mm}$ with Ceftazidime $(30 \mu \mathrm{g}), \leq 25 \mathrm{~mm}$ with Ceftriaxone $(30 \mu \mathrm{g})$, and $\leq 27 \mathrm{~mm}$ with Cefotaxime $(30 \mu \mathrm{g})$ were identified. Confirmation of ESBL production was done by combined disc diffusion method. This test was done by using a disk of Ceftazidime (30 $\mu \mathrm{g})$ alone and a disk of Ceftazidime + Clavulanic acid (30 $\mu \mathrm{g} / 10 \mu \mathrm{g})$ is used. Both discs were placed at $25 \mathrm{~mm}$ apart, center to center, on a lawn culture of test isolate on Muller Hinton Agar (MHA) plate and incubated overnight at $37^{\circ} \mathrm{C}$. A difference in zone diameters with or without clavulanic acid of $\geq 5 \mathrm{~mm}$ confirmed ESBL production.

Quality control was done by non - ESBL producing organism (Escherichia coli ATCC 25922) and an ESBL producing organism (Klebsiella pneumoniae ATCC 700603). 


\section{Results and Discussion}

Blood culture is positive in 134 (67\%) among 200 suspected cases of neonatal septicemia. Gram negative isolates are seen in 94 $(70.15 \%)$ cases whereas Gram positive isolates were seen in $35(26.11 \%)$ cases. The common organism isolated are Klebsiella pneumoniae 53 (39.55\%) followed by Escherichia coli $27 \quad(20.15 \%)$ and Staphylococcus aureus 25 (18.66\%) (Table 1).

Early onset neonatal septicemia (EONS) is seen in $138(69 \%)$ cases while late onset neonatal septicemia (LONS) is seen in 62 $(31 \%)$ cases. The distribution of culture positivity in cases of EONS and LONS is given in Table 2.

ESBL production is seen in 41/80 isolates of Klebsiella pneumoniae and Escherichia coli. The ESBL production is more seen in Klebsiella 29 / 53 (54071\%) as compared to Escherichia coli 12/27 (44.44\%) (Table 3).

Among the nonfermenters high ESBL production is seen in Acinetobacter species $2 /$ $6(33.33 \%)$ and Pseudomonas aeruginosa $1 /$ $8(12.5 \%)$. Multidrug resistance is seen in most of the ESBL producing strains which is higher than that seen in no ESBL producing strains (Table 3).

Neonatal septicemia remains as important cause of morbidity and mortality in developing countries along with developed countries. The accurate and timely identification of etiological agent and their resistance pattern are essential to combat neonatal septicemia. According to other studies, ESBL strains especially E. coli and Klebsiella Species have frequently implicated in neonatal septicemia at tertiary care center (Krishna et al., 2007, Chandel et al., 2011).
The blood culture positivity rate among neonates in current study was $67 \%$. A wide variation in blood culture positivity has been reported over the years from different centers of our country. This was similar to results of Nandy et al., (2007) and Yashwant Rao et al., (2012) and contrast to results of Rajendraprasad et al., (2013) and Khanna et al., (2016).

In our study, it was found that EONS (69\%) was more common than LONS (31\%). The EONS may be due to low birth weight, caesarian section, prolonged rupture of membranes $(\geq 12 \mathrm{hrs}$.) and chorioamnionitis as documented in our study. Similar results were observed in Agnihotri et al., (2004).

In the present study, Gram negative isolates were common $(70.15 \%)$ among all culture positive cases of neonatal septicemia as compared to Gram positive isolates $26.12 \%$ and Candida species $3.73 \%$. This was in line with results of Movahedian et al., (2007) and Zaki et al., (2009).

In the present study, Klebsiella pneumoniae (39.55\%) and E. coli $(20.15 \%)$ were common Gram negative organisms isolated from cases of neonatal septicemia. Staphylococcus aureus (18.66\%) and Coagulase negative Staphylococcus species $(6.72 \%)$ were found to be frequently isolated Gram positive organisms. This was is in line with Girish $e t$ al., (2012) and Pengsaa et al., (1995).

In the present study, significant no. of ESBL production was seen among Klebsiella pneumoniae (54.17\%) and E. coli $(44.44 \%)$. This was similar to results of Khanna et al., 2016, Prem Mishra et al., 2018 and Gandhi et al., 2013.

In the present study, $89-100 \%$ resistance against $3^{\text {rd }}$ generation cephalosporins was observed among ESBL producing strains of 
Klebsiella pneumoniae and E. coli. Similar results reported by Islam et al., 2014 which reported all ESBL positive strains of E. coli were resistant to Cefotaxime, Ceftriaxone and
Ceftazidime as compared to non ESBL isolates $(30-71 \%)$. This was in line with Sharma et al., (2015) (Table 5).

Table.1 Bacteriological profile of Neonatal Septicemia

\begin{tabular}{|l|c|c|c|}
\hline \multicolumn{1}{|c|}{ Organisms } & EONS & LONS & Total \\
\hline Gram positive organisms & $\mathbf{2 4}(\mathbf{2 6 . 3 7 \%})$ & $\mathbf{1 1}(\mathbf{2 5 . 5 8 \% )}$ & $\mathbf{3 5}(\mathbf{2 6 . 1 2 \%})$ \\
\hline Staphylococcus aureus & $17(18.68 \%)$ & $8(18.60 \%)$ & $25(18.66 \%)$ \\
\hline $\begin{array}{l}\text { Coagulase Negative } \\
\text { Staphylococcus species }\end{array}$ & $6(6.60 \%)$ & $3(6.98 \%)$ & $9(6.72 \%)$ \\
\hline Micrococcus species & $1(1.1 \%)$ & $0(0.00 \%)$ & $1(0.07 \%)$ \\
\hline Gram negative organisms & $\mathbf{6 4}(\mathbf{7 0 . 3 3 \% )}$ & $\mathbf{3 0}(\mathbf{6 9 . 7 7 \% )}$ & $\mathbf{9 4}(\mathbf{7 0 . 1 5 \% )})$ \\
\hline Klebsiella pneumoniae & $35(38.46 \%)$ & $18(41.86 \%)$ & $\mathbf{5 3}(\mathbf{3 9 . 5 5 \% )})$ \\
\hline Escherichia coli & $21(23.08 \%)$ & $6(13.95 \%)$ & $\mathbf{2 7}(\mathbf{2 0 . 1 5 \% )})$ \\
\hline Pseudomonas aeruginosa & $4(4.4 \%)$ & $4(9.30 \%)$ & $\mathbf{8 ( 5 . 9 7 \% )}$ \\
\hline Acinetobacter species & $4(4.4 \%)$ & $2(4.65 \%)$ & $\mathbf{6 ( 4 . 4 8 \% )}$ \\
\hline Candida species & $\mathbf{3 ( 3 . 3 \% )}$ & $\mathbf{2 ( 4 . 6 5 \% )}$ & $\mathbf{5 ( 3 . 7 3 \% )}$ \\
\hline Total & $\mathbf{9 1}$ & $\mathbf{4 3}$ & $\mathbf{1 3 4}$ \\
\hline
\end{tabular}

Table.2 Distribution of culture positive cases among EONS \& LONS cases

\begin{tabular}{|c|c|c|c|}
\hline $\begin{array}{c}\text { Age of onset of } \\
\text { septicemia }\end{array}$ & $\begin{array}{c}\text { Early onset } \\
\text { septicemia }\end{array}$ & $\begin{array}{c}\text { Late onset } \\
\text { septicemia }\end{array}$ & Total \\
\hline Culture Positive & $91(65.94 \%)$ & $43(69.35 \%)$ & $\mathbf{1 3 4}(\mathbf{6 7 \%})$ \\
\hline Culture Negative & $47(34.06 \%)$ & $19(30.65 \%)$ & $\mathbf{6 6}(\mathbf{3 3 \%})$ \\
\hline Total & $\mathbf{1 3 8 ( 6 9 \% )}$ & $\mathbf{6 2 ( 3 1 \% )}$ & $\mathbf{2 0 0}$ \\
\hline
\end{tabular}

Table.3 Resistance Pattern among ESBL producing and non producing isolates

\begin{tabular}{|c|c|c|c|c|c|c|c|c|}
\hline \multirow{2}{*}{$\begin{array}{l}\text { Organisms } \\
\text { Antibiotics }\end{array}$} & \multicolumn{2}{|c|}{$\begin{array}{l}\text { K. pneumoniae } \\
(n=53)\end{array}$} & \multicolumn{2}{|c|}{$\begin{array}{l}\text { E. coli } \\
(\mathbf{n}=27)\end{array}$} & \multicolumn{2}{|c|}{$\begin{array}{c}\text { Pseudomonas } \\
(\mathbf{n}=\mathbf{8})\end{array}$} & \multicolumn{2}{|c|}{$\begin{array}{c}\text { Acinetobacter sp } \\
(\mathbf{n}=\mathbf{6})\end{array}$} \\
\hline & $\begin{array}{c}\text { ESBL } \\
(n=29)\end{array}$ & $\begin{array}{c}\text { Non } \\
\text { ESBL } \\
(\mathbf{n}=\mathbf{2 6})\end{array}$ & $\begin{array}{l}\text { ESBL } \\
(\mathbf{n} \\
=12)\end{array}$ & $\begin{array}{c}\text { Non } \\
\text { ESBL } \\
(\mathbf{n}=15)\end{array}$ & $\begin{array}{l}\text { ESBL } \\
(n=1)\end{array}$ & $\begin{array}{c}\text { Non } \\
\text { ESBL } \\
(\mathbf{n}=7)\end{array}$ & $\begin{array}{l}\text { ESBL } \\
(n=2)\end{array}$ & $\begin{array}{l}\text { Non } \\
\text { ESBL } \\
(n=4)\end{array}$ \\
\hline Amikacin & 4 & 5 & 5 & 3 & 0 & 6 & 2 & 2 \\
\hline Gentamycin & 21 & 17 & 4 & 4 & 0 & 3 & 2 & 2 \\
\hline Cefotaxime & 26 & 8 & 12 & 5 & 1 & 4 & 2 & 4 \\
\hline Ceftriaxone & 27 & 9 & 10 & 4 & 1 & 4 & 2 & 3 \\
\hline Ceftazidime & 27 & 8 & 12 & 5 & 1 & 5 & 2 & 4 \\
\hline Cefepime & 22 & 5 & 9 & 3 & 1 & 2 & 1 & 3 \\
\hline Imipenem & 7 & 3 & 2 & 3 & 0 & 3 & 1 & 1 \\
\hline Ciprofloxacin & 6 & 4 & 3 & 2 & 0 & 2 & 0 & 3 \\
\hline
\end{tabular}


Table.4 ESBL production in Gram negative bacterial isolates

\begin{tabular}{|l|c|c|c|}
\hline \multicolumn{1}{|c|}{ Organisms } & $\begin{array}{c}\text { No. of isolates } \\
\text { tested for ESBL } \\
\text { production }\end{array}$ & $\begin{array}{c}\text { No. of isolates } \\
\text { producing ESBL }\end{array}$ & Percentage \\
\hline Klebsiella pneumoniae & 53 & 29 & $\mathbf{5 4 . 7 1}$ \\
\hline Escherichia coli & 27 & 12 & $\mathbf{4 4 . 4 4}$ \\
\hline Pseudomonas aeruginosa & 8 & 1 & $\mathbf{1 2 . 5}$ \\
\hline Acinetobacter species & 6 & 2 & $\mathbf{3 3 . 3 3}$ \\
\hline TOTAL & $\mathbf{9 4}$ & $\mathbf{4 4}$ & $\mathbf{4 6 . 8 0}$ \\
\hline
\end{tabular}

Imipenem shows $16-50 \%$, aminoglycosides like Amikacin 14- 42\% and Gentamycin $33-$ $72 \%$ shows resistance for ESBL producing Klebsiella pneumoniae and E. coli. This was in line with results of Prem Mishra et al., 2018.

In conclusion, testing for ESBL production is not routinely done by most of tertiary care centers. This may leads to ESBL producing isolates within tertiary care centers particularly in NICU. So empirical therapy in NICU should be regularly monitored according to the prevalence of ESBL producing organisms in tertiary care centers.

\section{References}

Agnihitri N, Kaistha N and Gupta V. 2004. Antimicrobial susceptibility of isolates from neonatal septicemia. Jpn. J. Inefect. Dis.; 57: 273 - 275.

Ashsish Khanna, Menka Khanna and Manmeet Gill. 2016. ESBL producing Gram Negative Bacteria - A Cause of Concern in Neonatal Septicemia in a Tertiary care Hospital. Int J. Curr. Micro. Appl. Sci; 5: 807 - 813.

Ballot D, Nana T, Sriruttan C. et al., 2012. Bacterial bloodstream in neonates in a developing country. Pediatrics.: $1-6$.

Chaudhary U, Aggarwal R. 2004. Extended spectrum $\beta$ lacatmases (ESBL) - An emerging threat to clinical therapeutics. Ind. J. Med. Microbiol; 22: $75-80$.
Choudhary HR, Hassan MA, Habibullah M. 2007. Neonatal sepsis and use of antibiotic in tertiary care hospital. Pak. J. Med. Sci.; 23 (1): 78 - 81.

Dinesh Chandel, Judith Johnson, Rama Chaudhary, Nidhi Sharma et al., 2011. Extended spectrum $\beta$ lactamases producing Gram negative bacteria causing neonatal sepsis in India in rural and urban settings. J. of Med. Microbiol; 60: 500 - 507 .

Islam MS, Yusuf MA, Islam MB, Jahan WA. 2014. Frequency of ESBL in surgical site infection in a Tertiary care Hospital. J. Curr. Adv. Med. Res; 1: 25-29.

Jain A., Roy I, Gupta MK, Kumar M, Agarwal SK. 2003. Prevalence of extended spectrum $\beta$ lactamases producing Gram negative bacteria in septicemic neonates in tertiary care hospital. J. Med. Microbiol; 52: 421 425.

Krishna BVS, Patil AB, Chndrashekhar M. 2007. Extended spectrum $\beta$ lactamases producing Klebsiella pneumoniae in neonatal care unit. Ind. J. Pediatr; 74: $627-630$.

Lebessi E, Dellagrammaticas H, Tassios PT, Tzouvelekis LS, Loannidou S. 2002. Extended spectrum beta lactamases producing Klebsiella pneumoniae in a neonatal intensive care unit in the high prevalence area of Athens. Greece $J$. Clin. Microbiol. 40: 799 - 804. 
Movahedian AH, Moniri R, Mosayebi Z.. 2006. Bacterial culture of neonatal sepsis. Iranian J. Publ. Health.; 35 (4): $84-89$.

Murthy DS, Gyaneshwari M. 2007. Blood cultures in pediatric patients: A study of clinical impact. Ind J. Med Microbiol.; 25: $220-224$.

Nandy M, Dutta S, Ganguly S, Paul DK, Bandopadhyay M, Mukhopadhyay P. 2007. Changing spectrum of Neonatal septicemia. N. R. S. Medical College and Hospital Experience. The Child and Newborn; 11 (1): 3 - 6.

Pengsaa K, Taksaphan S. 1995. Neonatal septicemia in Srinagacind Hospital in four years. Thai J. of Pediatr; 34 (3): $151-159$.

Prem Mishra, Dakshina Bishi, Ved Prakash, Anil Kumar, Varun Goyal. 2018. Extended Spectrum $\beta$ Lactamases Producing Lactose Fermenters Causing Neonatal Septicemia in a Tertiary Care Center in Uttar Pradesh. Int. J. Contemporary Med. Res.; 5 (4): D9 D14.

Rajendraprasad BP, Basavraj KN, Antony B. 2013. Bacterial spectrum of neonatal septicemia with their antibiogram with reference to various predisposing factors in a tertiary care hospital in Southern India. Ann Trop. Med. Public Health; 6: 96 - 99.

Sharma RS, Tiwari M. 2015. Neonatal septicemia in NICU of a tertiary care center in north India due to extended spectrum beta lactamases (ESBL) producing bacteria. Ind. J. Basic and Appl. Med. Res; 5: 183 - 190.

Tripathi S., Malik G.K. 2010. Neonatal sepsis: Past, present and Future; a review article. Int. J. Med. Update, 5: $45-54$.

Wayne P. A. 2010. Clinical and Laboratory Standards Institute. Performance Standards for Antimicrobial Susceptibility Testing; $20^{\text {th }}$ international supplement M100 - S20.

Yashwant Rao, Tanu Midha, Atul Garg, Jaya Garg et al., 2012. Neonatal septicaemia in north India due to extended spectrum beta lactamases (ESBL) producing Gram negative bacteria. Int. J. Pharma and Biosciences; 3: $282-290$.

Zaki M.El.S, Syed H El. 2009. Evaluation of Microbiologic and haematologic parameters and E - selectin as early predictors for the outcome of neonatal sepsis. Arch. Pathol. Lab. Med.133: $1291-1296$.

\section{How to cite this article:}

Wadile Rahul Gopichand. 2019. Prevalence of ESBL in Isolates of Klebsiella pneumoniae and E. coli in Suspected Cases of Neonatal Septicemia in Tertiary Care Hospital in North Maharashtra, India. Int.J.Curr.Microbiol.App.Sci. 8(05): 569-574. doi: https://doi.org/10.20546/ijcmas.2019.805.066 